Are Basal Transgressive Sands Chiefly Inlet-filling Sands?*

NARESH KUMAR and J.E. SANDERS

Department of Geology, Barnard College, Columbia University, New York, N. Y.

\title{
Introduction
}

When the sea transgresses across sandy sediments, it typically forms barrier islands. Between the barriers and the mainland are lagoons that tend to fill with fine sediments brought in by the tides. The water flows in and out of the lagoons through tidal inlets, which the tidal currents locally scour to depths ranging from 20 to 100 feet below the level of mean low water. Depending on the directions from wich waves approach the coast, the tidal inlets may migrate systematically in one direction. As the inlets are forced to shift laterally by the longshore drift that is powered by the waves, the tidal currents eorde the banks of the inlet on one side and deposit sediment on the opposite side. The ensuing lateral migration compares with the sideways shifting of the channel of a meandering stream on land. The result of inlet migration is to leave behind thick "channel deposits" under those portions of the barrier island through which the inlet has migrated (Hoyt and Henry, 1965, 1967). Theoretically, lateral migration of inlets parallel to the coast and landward shifting of barriers at right angles to the coast could form blankets of sand that would be preserved even if the waves washed away all other kinds of sand down to or slightly below the level of mean low water. If this analysis is correct, then on the continental shelf lying seaward of barrier islands the modern sands which have been influenced by the rising sea might consist largely of inlet sands.

In order to test these ideas, in the summer of 1969 we began a study of the history of migration, nature of sediments, kinds of sedimentary structures, and sequence of strata formed by inlet migration at Fire Island Inlet, which is situated 35 miles east of New York City on the south shore of Long Island (Fig. 1).

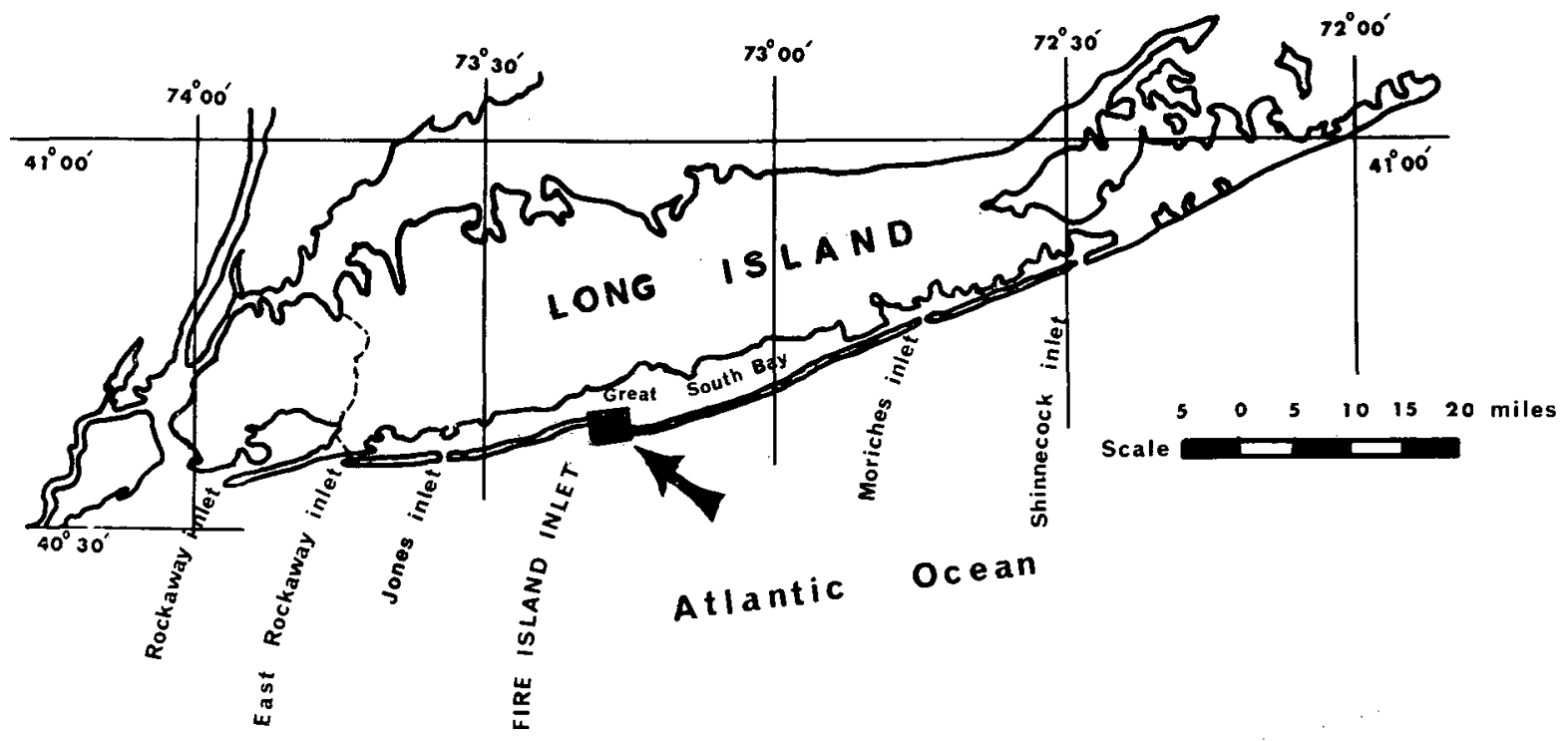

Figure 1 - Map showing the location of Fire Island Inlet and other inlets associated with barriers along the south shore of Long Island, New York. Rectangle marks position of 1955 map in Figure 2. 
Figure 2 - Maps showing the successive westward migra. tion of Fire Island Inlet during the period 1834 to 1955. In 1834, the inlet existed within $500 \mathrm{ft}$. of the Fire Island Lightouse. By 1 39 , the inlet ha ${ }^{\circ}$ migrated 5 miles westwards. A jetty con-ructed in 1939 stoppe. further migration of Fire Island for some time but by 1950 , the area east of the jetty had overflowed with sand anu til- -pit had started to grow farther west again. The position of inlet is now maintaine y requent dredging. (Based on maps prepared by U.S. Army Corps of Engineers.)

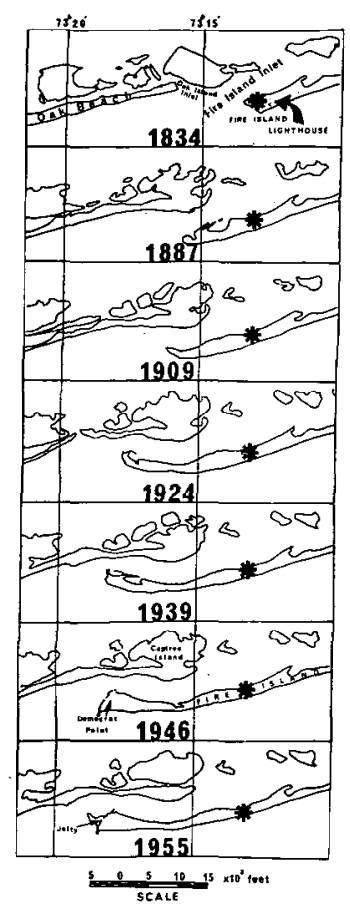

Migration of Fire Island Inlet

(1834-1955)

Objectives of Present Study

Our work is intended to achieve the following three objectives: (1) to define the sequence of sedimentary structures and textures of sands in a modern inlet (in our case, Fire Island Inlet) from the bottom of the channel up to the dunes; (2) to look for the same structures and textures in those parts of the barrier island through which the inlet is known to have migrated; (3) to see if we can recognize parts of the "inlet-sequence" in cores available to us from the shelf seaward of Fire Island.

\section{Present status of the Project}

(1) We have diready collected box-cores and tube-cores by hand on the spit at the edge of the migrating inlet, dug trenches, and collected samples. We have also mapped this spit in detail at various times and have studied aerial photographs of the inlet ranging from most recent ones to photographs as old as 1939. Epoxy-peels have been prepared from the box-cores using the methods described by Burger, Klein, and sanders (1969). Our procedure with tube-cores is first to make $x$-radiographs and then to split the cores longitudinally and make epoxy-peels from one of the faces of the opened core. Depending upon the, size of our financial support, the deeper parts of the inlet will be sampled in the summer of 1970; either by box-coring from a small research ship or by divers working from a small boat using the methods of Sanders (1968).

(2) We propose to drill deep (up to 100') borings on Fire Island. At least one of these bore holes will be located east of the last-recorded position of Fire Island Inlet. Various charts and maps record a steady westward migration of Fire Island inlet of 5 miles during the period 1825-1939 (Fig. 2). These borings should provide samples of a complete "inlet-sequence".

(3) We have available to us for study a suite of cores from the Great South Bay and shelf off Fire Island. At various times during the last 5 years, G.M. Friedman and John E. Sanders have collected cores from these areas which will be used for this study (Friedman, 1966; Friedman and others, 1968; Friedman and Gavish, 1970). The U.S. Army Corps of Engineers have also made available their long (longest $17 \mathrm{ft}$ ) cores from the shelf off Fire Island.

In addition to studying the sedimentary structures that may characterize various layers in any "inlet-sequence", we also plan to make size analyses on samples from various environments and give detailed statistical treatment to the particle-size data.

Preliminary results of this study have been presented by Kumar and Sanders (1970). 
Acknowledgements

Sincere thanks are due to the Geological Society of America for Penrose Bequest Grant No. 1225-69; to the Society of the Sigma Xi; and to the Department of Geology, Columbia University, for financial support of this project during the sumnex of 1969 . We also appreciate the generous co-operation of the U.S. Army Corps of Engineers, who have provided us with various charts, maps, and cores.

\section{References cited}

BURGER, J.A., KLEIN, G.deV., and SANDERS, J.E., 1969, A field technique for making epoxy-peels in sandy sediments saturated with saltwater: Jour. Sed. Petrology, v. 39, p. 338-34l.

FRIEDMAN, G.M., 1966, Study of continental shelf and slope on the coasts of Long Island, New York, and New Jersey: Maritime Sediments, v. 2, p. 21-22.

and others, 1968, Chemical changes in interstitial waters from continental shelf sediments: Jour. Sed. Petrology, v, 38, p. 1313-1319.

and Gavish, E., 1970, Chemical changes in interstitial waters from lagoonal, estuarine, tidal marsh, and deltaic environments: Geol. Soc. America,, Abstracts with Programs, v. 2, p. 20-21.

HOYT, J.H. and HENRY, V.J., Jr., 1965, Significance of inlet sedimentation in the recognition of ancient barrier islands: Wyo. Geol. Assoc., Guidebook 19th. Field Conf., p. 190-194.

1967, Influence of island migration on barrier-island sedimentation: Geol. Soc. America, Bull., v. 78, p. 77-86.

KUMAR, N. and SANDERS, J.E., 1970, Geologic implications of migration of Fire Island Inlet: Geol. Soc. Am. Abstracts with Programs, v. 2, p. 27.

SANDERS, J.E., 1968, Diver-operated simple hard tools for coring nearshore sands: Jour. Sed. Pet., v. 38, p. $1381-1386$. 